(C) 2016 IEEE. Personal use of this material is permitted. Permission from IEEE must be obtained for all other uses, in any current or future media, including reprinting/republishing this material for advertising or promotional purposes, creating new collective works, for resale or redistribution to servers or lists, or reuse of any copyrighted component of this work in other works. 


\title{
A Simplified Finite-State Predictive Direct Torque Control for Induction Motor Drive
}

\author{
Md. Habibullah, Student Member, IEEE, Dylan Dah-Chuan Lu, Senior Member, IEEE, Dan Xiao, and Muhammed \\ Fazlur Rahman, Fellow, IEEE
}

\begin{abstract}
Finite-state predictive torque control (FS-PTC) is computationally expensive, since it uses all voltage vectors available from a power converter for prediction and actuation. The computational burden is rapidly increased with the number of voltage vectors and objectives to be controlled. Moreover, designing a cost function with more than two control objectives is a complex task. This paper proposes a simplified algorithm based on a new direct torque control (DTC) switching table to reduce the numbers of voltage vectors to be predicted and objectives to be controlled. The new switching table also assists to reduce average switching frequency and its variation range. As a result, the cost function is simplified by not requiring to include the frequency term. Experimental results show that the average execution time and the average switching frequency for the proposed algorithm are greatly reduced without affecting the torque and flux performances achieved in the conventional FS-PTC.
\end{abstract}

Index Terms-Predictive torque control, simplified algorithm, execution time, average switching frequency, Torque and flux ripple, induction motor (IM).

\section{INTRODUCTION}

$\mathbf{R}$ ECENTLY, predictive torque control (PTC) strategies have received wide attention in research communities due to their intuitive features, easy implementation, and easy inclusion of nonlinearities and constraints of model predictive control (MPC) [1]-[7]. Finite-state predictive torque control (FS-PTC) is one of the most attractive PTC strategies. In FSPTC, torque and stator flux are predicted for the finite number of admissible switching states of a voltage source inverter (VSI). The switching state that minimizes torque and flux ripples most is finally chosen as the optimal switching state, and is obtained by actuating a predefined cost function. Several targets, variables, and constraints with weighting factors can be included in the cost function and simultaneously controlled. The selected optimal switching state is directly applied to the converter to produce the voltage vector to be applied to the motor terminal in the next sampling instant, without requiring an intermediate modulation stage [2]. Another important advantage of PTC is that it has no inner current control loop.

Manuscript received May 30, 2015; revised October 12, 2015 and November 20, 2015; accepted December 20, 2015.

Copyright (c) 2016 IEEE. Personal use of this material is permitted. However, permission to use this material for any other purposes must be obtained from the IEEE by sending a request to pubs-permissions@ieee.org.

M. Habibullah and D.D.-C. Lu are with the School of Electrical and Information Engineering, The University of Sydney, Sydney, N.S.W. 2006, Australia (e-mail:md.habibullah@sydney.edu.au, dylan.lu@sydney.edu.au).

D. Xiao and M.F. Rahman are with the School of Electrical Engineering and Telecommunications, University of New South Wales, Sydney, N.S.W. 2052, Australia (e-mail:d.xiao@unsw.edu.au, f.rahman@unsw.edu.au).
Moreover, PTC structure is simpler compared to the classical complex switching table based direct torque control (DTC) [8].

Generally, several types of power converters are employed to produce the voltage vectors applied to the motor terminals, such as two-level VSI (2L-VSI), multilevel inverters, and matrix converters [2]. Among them, 2L-VSI is extensively used in industry applications [1]. For medium and high power applications, multilevel converters-most prominently threelevel inverters, are more preferable than 2L-VSI. However, in a three-level inverter, the numbers of admissible switching states are 27 and all switching states should be evaluated through the cost function, which is inevitably time consuming. The computational burden grows rapidly with the number of admissible switching states of an inverter resulting in low sampling frequency of the control algorithm. Hence, multilevel converter strategies may not still be widely used with FS-PTC in industry applications. In fact, consideration of all eight admissible switching states of 2L-VSI becomes computationally expensive to achieve complete benefits, such as torque ripple reduction by using multiobjective optimization and/or long prediction horizon $N_{p} \geq 2$, of FS-PTC.

In recent years, research has been carried to reduce the number of calculations in model predictive control [9]-[16]. In [9], a computationally efficient predictive direct torque control for medium voltage drives is proposed. By adopting branch and bound algorithm and by discarding some optimal sequences, the number of switching sequences is reduced. Another reduced switching selection method is proposed in [10] which reduces the torque ripple by using long prediction horizon, even though the number of calculations is still higher. There are several other techniques to reduce the number of calculations and thus to simplify the design of MPC, such as single prediction method [11], sector distribution method [11], [12], choosing a subset of adjacent vectors [13], modified switching algorithm [14], double-vector-based approach [15], and graphical algorithm [16]. The former techniques have been applied to power converters only for current, voltage and/or power control, where the objective function is relatively easy to design. The control algorithms may not work for motor drives, since the control aspects are complex and completely different from those considered in [11]-[16]. For a speed sensorless motor drives [17], the reduction of the computational burden is important because the execution time of a speed observer is significant compared with the control duration. In this case, the controller itself should be computationally efficient. Recently, a deadbeat (DB) solution is proposed in [18] to reduce the computational burden of the original FS-PTC. The 
controller seems to be effective for a multilevel converter or for a long predictive horizon $\left(N_{p}>1\right)$. However, complex calculations to find out DB voltage vector (VV) outweigh the advantage of the controller for a short prediction horizon $\left(N_{p}=1\right)$. Reference [19] has also reported a computationally efficient FS-PTC for IM drive by reducing the number of prediction vectors. The voltage vectors required for prediction and actuation to find out the optimal one are called prediction vectors. Analysis has been carried out only for medium speed operation. Moreover, drawback of the control algorithm and its possible solution, average switching frequency of the inverter and its variation range, and designing of the cost function have not been addressed in the analysis.

To date, a key issue in implementation of FS-PTC is the selection of weighting factors used in the cost function [2]. The weighting factors are used to tune the importance or cost of a particular target in relation to the other control targets. Different strategies using online and offline search procedures have been proposed in [20], [21], which are strongly dependent on system parameters and require a comprehensive mathematical analysis. Moreover, when the desired control objectives are more than two, trial and error methods are used running computer simulations, which are extremely time consuming [22]-[24]. To avoid this, a multiobjective rankingbased strategy is proposed in [25] for PTC. However, the computational burden is greatly increased, even for the $2 \mathrm{~L}$ VSI, due to the use of all admissible inverter switching states. Moreover, the aforementioned algorithm is only applied for two control objectives, whereas, in general, including switching frequency with torque and flux errors, three control objectives are required for PTC [26]. Hence, designing a cost function with appropriate weights, especially when the control objectives are more than two, is very complex.

This paper presents a simplified finite-state predictive direct torque control (FS-PDTC) based on a new switching table to reduce the number of prediction vectors and, therefore, to reduce the computational burden. The position of stator flux and sign of torque deviation have been taken into account to lessen the number of voltage vectors. Two adjacent forward voltage vectors with an appropriate zero vector are always selected as prediction vectors, and thus average switching frequency of the power converter and its variation range are reduced when compared with a conventional FS-PTC strategy. There is no need to include a frequency term in the cost function, which yields a simpler design of cost function compared with the conventional FS-PTC. In order to make a comparison with the existing FS-PTC scheme, also for simplicity, a 2L-VSI is employed to produce necessary voltage vectors.

\section{INDUCTION MOTOR MODEL}

The state space model of induction motor (IM) can be described by the following equations (1)-(6):

$$
\begin{gathered}
\vec{v}_{s}=R_{s} \vec{i}_{s}+\frac{d \vec{\psi}_{s}}{d t} \\
0=R_{r} \vec{i}_{r}+\frac{d \vec{\psi}_{r}}{d t}-j \omega_{e} \vec{\psi}_{r}
\end{gathered}
$$

$$
\begin{gathered}
\vec{\psi}_{s}=L_{s} \vec{i}_{s}+L_{m} \vec{i}_{r} \\
\vec{\psi}_{r}=L_{m} \vec{i}_{s}+L_{r} \vec{i}_{r} \\
T_{e}=1.5 p \Im m\left\{\vec{\psi}_{s}^{*} \cdot \vec{i}_{s}\right\} \\
J \frac{d \omega_{m}}{d t}=T_{e}-T_{l}
\end{gathered}
$$

where $\vec{v}_{s}$ is the stator voltage vector, $\vec{i}_{s}$ is the stator current vector, $\vec{i}_{r}$ is the rotor current vector, $\vec{\psi}_{s}$ is the stator flux vector, $\vec{\psi}_{r}$ is the rotor flux vector, $T_{e}$ is the electromagnetic torque, $T_{l}$ is the load torque, $\omega_{m}$ is the rotor angular speed, $\omega_{e}$ is the rotor angular frequency, $p$ is the number of pole pairs, and the others are the system parameters.

\section{CONVEntional FS-PTC MODEL AND ITS LIMITATIONS}

A conventional FS-PTC model comprises two steps: prediction and cost function optimization, as shown in Fig. 1. The performance and required computational burden of the model are analyzed for a two-level voltage source inverter (2L-VSI). It is well known that a $2 \mathrm{~L}-\mathrm{VSI}$ produces eight voltage vectors $\mathbf{v}_{n}=\left\{\mathbf{v}_{0} \cdots \mathbf{v}_{7}\right\}$, as shown in Table I. The voltage vectors are presented in stationary reference frame $(\alpha-\beta)$. All the switching states $s=\left\{s_{a} s_{b} s_{c}\right\}$ of the inverter for three phase

\begin{tabular}{|c|c|c|}
\hline $\mathbf{v}_{n}$ & $s=\left[s_{a} s_{b} s_{c}\right]$ & $\mathbf{v}=\mathbf{v}_{\alpha}+\jmath \mathbf{v}_{\beta}$ \\
\hline 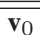 & $\begin{array}{lllllllllll}0 & 0 & 0\end{array}$ & 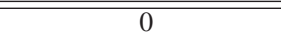 \\
\hline $\mathbf{v}_{1}$ & 100 & $2 / 3 V_{d c}$ \\
\hline $\mathbf{v}_{2}$ & 110 & $1 / 3 V_{d c}+\jmath \sqrt{ } 3 / 3 V_{d c}$ \\
\hline $\mathbf{v}_{3}$ & 010 & $-1 / 3 V_{d c}+\jmath \sqrt{ } 3 / 3 V_{d c}$ \\
\hline $\mathbf{v}_{4}$ & 0111 & $-2 / 3 V_{d c}$ \\
\hline $\mathbf{v}_{5}$ & $\begin{array}{lll}0 & 0 & 1\end{array}$ & $-1 / 3 V_{d c}-\jmath \sqrt{ } 3 / 3 V_{d c}$ \\
\hline $\mathbf{v}_{6}$ & 101 & $1 / 3 V_{d c}-\jmath \sqrt{ } 3 / 3 V_{d c}$ \\
\hline $\mathbf{v}_{7}$ & 111 & 0 \\
\hline
\end{tabular}
$\{a, b, c\}$ are also shown in the Table I.

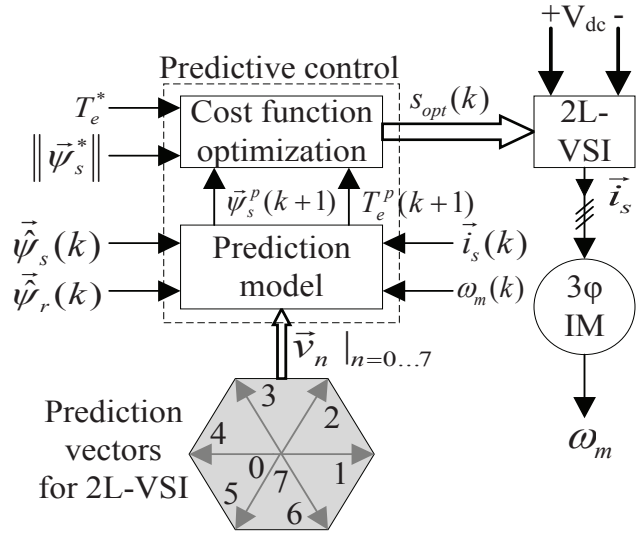

Fig. 1. Conventional FS-PTC scheme.

TABLE I

VOLTAGE VECTORS OF A 2L-VSI

In FS-PTC, estimations of stator flux $\overrightarrow{\hat{\psi}}_{s}$ and rotor flux $\overrightarrow{\hat{\psi}}_{r}$ are required based on the present measurements of stator current $\vec{i}_{s}$ and rotor speed $\omega_{m}$. Conventionally, rotor current 
model of IM is employed to estimate rotor flux. Then, the simple relation between stator and rotor flux is used to estimate stator flux. Hence, the estimations of rotor and stator flux can be expressed as

$$
\begin{gathered}
\frac{d \overrightarrow{\hat{\psi}}_{r}}{d t}=R_{r} \frac{L_{m}}{L_{r}} \vec{i}_{s}-\left(\frac{R_{r}}{L_{r}}-j \omega_{e}\right) \overrightarrow{\hat{\psi}}_{r} \\
\overrightarrow{\hat{\psi}}_{s}=\frac{L_{m}}{L_{r}} \overrightarrow{\hat{\psi}}_{r}+\sigma L_{s} \vec{i}_{s}
\end{gathered}
$$

where $\sigma=1-L_{m}^{2} / L_{s} L_{r}$ is the total leakage factor.

Using standard backward-Euler approximation, the discrete form of (7) and (8) can be obtained as

$$
\begin{gathered}
\overrightarrow{\hat{\psi}}_{r}(k)=\overrightarrow{\hat{\psi}}_{r}(k-1)+T_{s}\left[R_{r} \frac{L_{m}}{L_{r}} \vec{i}_{s}(k)-\right. \\
\left.\left(\frac{R_{r}}{L_{r}}-j \omega_{e}(k)\right) \overrightarrow{\hat{\psi}}_{r}(k-1)\right] \\
\overrightarrow{\hat{\psi}}_{s}(k)=\frac{L_{m}}{L_{r}} \overrightarrow{\hat{\psi}}_{r}(k)+\sigma L_{s} \vec{i}_{s}(k) .
\end{gathered}
$$

Then the estimated electromagnetic torque can be obtained as

$$
\hat{T}_{e}(k)=1.5 p \Im m\left\{\overrightarrow{\hat{\psi}}_{s}(k)^{*} \cdot \vec{i}_{s}(k)\right\} .
$$

Now the first step of predictive control is performed by predicting stator flux and torque. Actually, the selection of variables to be predicted is dependent on the desired objectives. More numbers of variables mean the controller requires more calculations. All possible voltage vectors $\left\{\mathbf{v}_{0} \cdots \mathbf{v}_{7}\right\}$ are evaluated to predict the desired objectives. Generally, stator voltage model of IM is used for stator flux prediction and can be expressed in discrete time steps as

$$
\vec{\psi}_{s}^{p}(k+1)=\overrightarrow{\hat{\psi}}_{s}(k)+T_{s} \vec{v}_{s}(k)-T_{s} R_{s} \vec{i}_{s}(k) .
$$

In order to predict the electromagnetic torque, stator current is also predicted. Hence, the predictions of stator current and torque can be expressed as

$$
\begin{array}{r}
\vec{i}_{s}^{p}(k+1)=\left(1+\frac{T_{s}}{\tau_{\sigma}}\right) \vec{i}_{s}(k)+\frac{T_{s}}{\left(\tau_{\sigma}+T_{s}\right)} \times \\
\left\{\frac{1}{R_{\sigma}}\left[\left(\frac{k_{r}}{\tau_{r}}-k_{r} j \omega_{e}(k)\right) \overrightarrow{\hat{\psi}}_{r}(k)+\vec{v}_{s}(k)\right]\right\} \\
T_{e}^{p}(k+1)=1.5 p \Im m\left\{\vec{\psi}_{s}^{p}(k+1)^{*} \cdot \vec{i}_{s}^{p}(k+1)\right\}
\end{array}
$$

where $k_{r}=L_{m} / L_{r}$ is the rotor coupling factor, $R_{\sigma}=$ $R_{s}+k_{r}^{2} R_{r}$ is the equivalent resistance referred to stator, $\tau_{\sigma}=L_{\sigma} / R_{\sigma}$ is the transient time stator constant, $L_{\sigma}=\sigma L_{s}$ is the leakage inductance, and $\tau_{r}=L_{r} / R_{r}$ is the rotor time constant. Since the rotor time constant is much greater than the sampling time and the rotor flux moves very slowly compared with the stator flux, it is a general practice to assume $\omega(k)=\omega(k+1)$ and $\psi_{r}(k)=\psi_{r}(k+1)$, respectively.

The predicted variables are evaluated by a predefined cost function. In FS-PTC, generally, the cost function includes absolute values of torque error $\left(T_{e}^{*}-T_{e}^{p}\right)$ and flux error $\left(\vec{\psi}_{s}^{*}-\vec{\psi}_{s}^{p}\right)$. Hence, the cost function can be defined as

$$
g=\left|T_{e}^{*}(k+1)-T_{e}^{p}(k+1)\right|+\lambda_{p}|| \vec{\psi}_{s}^{*}|-| \vec{\psi}_{s}^{p}(k+1)||
$$

where $T_{e}^{*}(k+1)$ is the reference torque and $T_{e}^{p}(k+1)$ is the predicted torque, $\vec{\psi}_{s}^{*}$ is the reference stator flux which is always kept constant and $\vec{\psi}_{s}^{p}(k+1)$ is the predicted stator flux. In this study, the weighting factor $\lambda_{p}$ sets the relative importance of the stator flux compared with the torque. Since the sampling time is very small, it is a common practice to assume $T_{e}^{*}(k)$ as $T_{e}^{*}(k+1)$.

For average switching frequency reduction, a switching transition term $n_{s w}$ is included in the cost function and can be defined as [27]

$$
n_{s w}=\sum_{x=\{a, b, c\}}\left|s_{x}(k+1)_{i}-s_{x}(k)\right|
$$

where $s_{x}(k+1)$ is the probable switching state for the next time instant $k+1, s_{x}(k)$ is the applied switching state to the inverter at the time instant $k$, and $i$ is the index of possible voltage vectors $\left\{\mathbf{v}_{0} \cdots \mathbf{v}_{7}\right\}$. The conventional FS-PTC with switching transition term in the cost function will be defined as $\operatorname{FS}-\mathrm{PTC}\left(\bar{f}_{s w}\right)$.

In order to protect over current, the cost function $g$ must include another term $I_{m}$ which is designed on the basis of maximum current capacity of the stator winding. Therefore, the term $I_{m}$ can be defined as

$$
I_{m}= \begin{cases}\infty, & \text { if }\left|\vec{i}_{s}^{p}(k+1)\right|>I_{\max } \\ 0, & \text { otherwise. }\end{cases}
$$

Thus, the complete cost function $g$ for the controller is

$$
\begin{array}{r}
g=\left|T_{e}^{*}(k+1)-T_{e}^{p}(k+1)\right|+\lambda_{p}|| \vec{\psi}_{s}^{*} \mid- \\
\left|\vec{\psi}_{s}^{p}(k+1)\right| \mid+\lambda_{n} n_{s w}+I_{m}
\end{array}
$$

where $\lambda_{n}$ is the weighting factor of $n_{s w}$. The fourth term $I_{m}$ does not need any weighting factor. Imposing of proper weighting factors on the other three different objectives is very difficult. The desired system performance may not be achieved due to improper selection of weighting factors.

Hence, the drawbacks of conventional FS-PTC can be summarized as follows:

1) All voltage vectors available from a power converter are evaluated for prediction and actuation, which is computationally expensive. The computational burden limits the sampling frequency.

2) When switching transition term is included in the cost function to reduce the average switching frequency, the computational burden is increased further. Moreover, the selection of weighting factors for three different objectives is difficult and thus designing a cost function is complex.

\section{PROPOSED FS-PDTC MODEL}

The structure of the proposed FS-PDTC is almost similar to the conventional FS-PTC, and shown in Fig. 2. The differences are the selection of prediction vectors $\mathbf{v}_{j}$ and the design of cost function, where $j$ may be three values among $n=\{0 \cdots 7\}$. In the conventional case, all voltage vectors of a $2 \mathrm{~L}-\mathrm{VSI}$ are 
employed for prediction and actuation. In the proposed FSPDTC, only three-one zero and two active vectors, of the possible eight voltage vectors are evaluated for the prediction and actuation. Hence, the computational burden is reduced significantly.

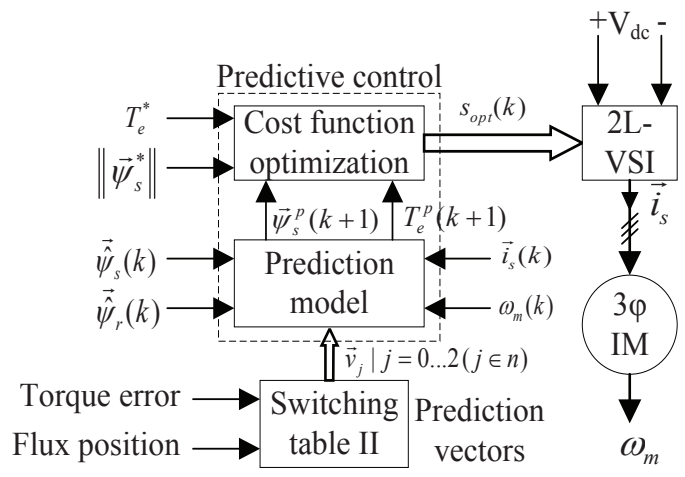

Fig. 2. Proposed FS-PDTC scheme.

\section{A. Selection of prediction vectors}

In this paper, a new switching table is proposed based on DTC strategy [8]. The prediction vectors from the switching Table I are selected using the present position of stator flux $\hat{\psi}_{s}$ and sign of torque deviation $\delta T_{e}=\left(T_{e}^{*}-\hat{T}_{e}\right)$. The position of stator flux $\hat{\theta}_{s}$ is estimated as

$$
\hat{\theta}_{s}=\arctan \left(\overrightarrow{\hat{\psi}}_{\beta s} / \overrightarrow{\hat{\psi}}_{\alpha s}\right) \text {. }
$$

A 2L-VSI produces six active vectors $\left\{\mathbf{v}_{\mathbf{1}}, \cdots, \mathbf{v}_{\mathbf{6}}\right\}$ and two zero vectors $\left\{\mathbf{v}_{\mathbf{0}}, \mathbf{v}_{\mathbf{7}}\right\}$. In this study, only $\mathbf{v}_{\mathbf{0}}$ is considered as the zero vector in the prediction and the actuation steps to reduce computational burden. The assumption is valid because there is no switching frequency term included in the cost function. After optimization, if the optimal voltage vector is a zero vector, an appropriate zero vector (either $\mathbf{v}_{\mathbf{0}}$ or $\mathbf{v}_{\mathbf{7}}$ ) is selected based on the applied optimal switching state at time instant $k$. Space distribution of all voltage vectors in the $\alpha-\beta$ plane is shown in Fig. 3. The active voltage vectors change periodically by an angle $\pi / 3 \mathrm{rad}$ steps, as shown in Fig. 3 . Accordingly, the $\alpha-\beta$ plane is divided into six sectors to identify the direction of rotation as

$$
(2 N-3) \pi / 6 \leq \Theta(N) \leq(2 N-1) \pi / 6
$$

where $\Theta$ is the sector and $N=\underset{\overrightarrow{\hat{\psi}}}{\overrightarrow{\psi_{s}}}, \cdots, 6$.

Let us consider the stator flux $\hat{\psi}_{s}$ is rotating in the counterclockwise direction. For a particular instant, the possible conditions of torque deviation are $\delta T_{e}>0, \delta T_{e}<0$, and $\delta T_{e}=0$, and flux deviation are $\delta \psi_{s}>0, \delta \psi_{s}<0$, and $\delta \psi_{s}=0$, where $\delta \psi_{s}=\left(\vec{\psi}_{s}^{*}-\overrightarrow{\hat{\psi}}_{s}\right)$. If $\overrightarrow{\hat{\psi}}_{s}$ is located in sector I and the torque deviation $\delta T_{e}>0$, then the voltage vectors which satisfy torque increase (TI) condition, as shown in Fig. 3, will be selected as prediction vectors. Hence, the possible active prediction vectors are two adjacent forward vectors $\mathbf{v}_{\mathbf{2}}\left(\begin{array}{lll}1 & 1 & 0\end{array}\right)$ and $\mathbf{v}_{\mathbf{3}}\left(\begin{array}{lll}0 & 1 & 0\end{array}\right)$, and represented by solid arrows on the tip of

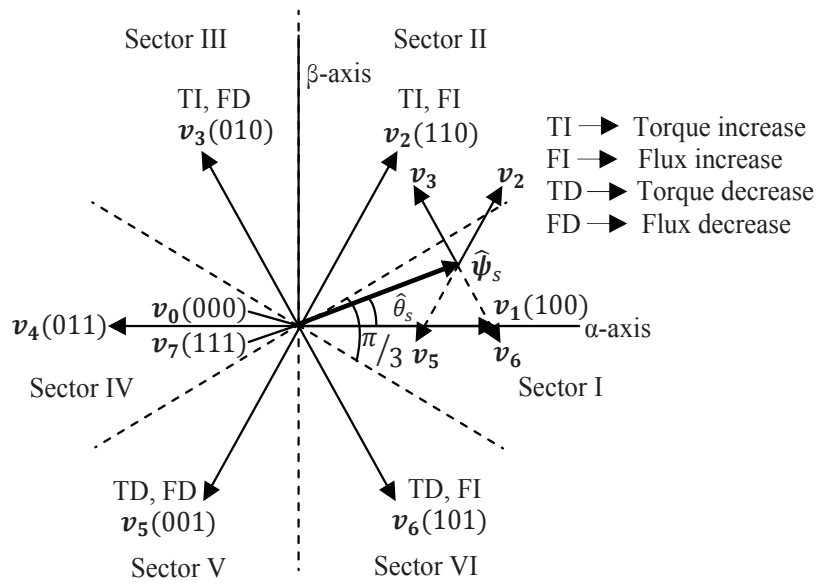

Fig. 3. Space distribution of all admissible voltage vectors of a 2L-VSI.

stator flux $\overrightarrow{\hat{\psi}}_{s}$, as shown in Fig. 3. The selection of two adjacent forward voltage vectors also ensures the possible condition of stator flux deviation $\delta \psi_{s}>0$ or $\delta \psi_{s}<0$. Similarly, for the same position of stator flux, if $\delta T_{e}<0$, the possible active prediction vectors are two adjacent backward vectors $\mathbf{v}_{\mathbf{6}}\left(\begin{array}{lll}1 & 0 & 1\end{array}\right)$ and $\mathbf{v}_{\mathbf{5}}\left(\begin{array}{lll}0 & 0 & 1\end{array}\right)$, and represented by dashed arrows on the tip of stator flux $\hat{\psi}_{s}$ in the Fig. 3. Generally, the active vectors are always employed with a zero vector for IM to reduce the torque and the flux ripples effectively. Inclusion of a zero vector also satisfies the possible conditions of $\delta T_{e}=0$ and $\delta \psi_{s}=0$. Hence, the total number of prediction vectors is three, while it was seven in conventional FS-PTC. The possible active prediction vectors for all the sectors are shown in Table II.

It is obvious that, if $\hat{\theta}_{s}(k-1)$ and $\hat{\theta}_{s}(k)$ lie in the same sector and the signs of $\delta T_{e}(k-1)$ and $\delta T_{e}(k)$ are similar, then maximum one switching transition is possible between two active vectors due to the selected prediction vectors. Hence, the proposed strategy of reduced prediction vectors also reduces the average switching frequency of the power converter.

TABLE II

STATOR FLUX POSITION AND TORQUE ERROR DEPENDENT ACTIVE PREDICTION VECTORS

\begin{tabular}{|l|l|l|l|l|l|l|}
\hline$\delta T_{e} \Theta$ & I & II & III & IV & V & VI \\
\hline$\delta T_{e}>0$ & $\mathbf{v}_{2}, \mathbf{v}_{3}$ & $\mathbf{v}_{3}, \mathbf{v}_{4}$ & $\mathbf{v}_{4}, \mathbf{v}_{5}$ & $\mathbf{v}_{5}, \mathbf{v}_{6}$ & $\mathbf{v}_{6}, \mathbf{v}_{1}$ & $\mathbf{v}_{1}, \mathbf{v}_{2}$ \\
\hline$\delta T_{e}<0$ & $\mathbf{v}_{5}, \mathbf{v}_{6}$ & $\mathbf{v}_{6}, \mathbf{v}_{1}$ & $\mathbf{v}_{1}, \mathbf{v}_{2}$ & $\mathbf{v}_{2}, \mathbf{v}_{3}$ & $\mathbf{v}_{3}, \mathbf{v}_{4}$ & $\mathbf{v}_{4}, \mathbf{v}_{5}$ \\
\hline
\end{tabular}

It is apparent from Fig. 3 that, another switching table based on $\hat{\theta}_{s}(17)$ and flux error $\delta \psi_{s}$ instead of torque error $\delta T_{e}$ can be developed. The possible active prediction vectors based on $\delta \psi_{s}$ for all the sectors are shown in Table III. However, relatively lower priority on stator flux (small value of weighting factor $\lambda_{p}$ ) in the cost function (20) has to be set compared with the $\delta T_{e}$ based switching table (see Table II) in order to achieve satisfactory torque and flux performance. It is because stator flux gets priority on torque when $\delta \psi_{s}$ based prediction vectors (see Table III) are considered. The performances in terms of computational burden, torque ripple, and flux ripple will be almost similar. However, $\delta T_{e}$ based prediction vectors are 
appropriate, since the torque is estimated based on the both stator flux and stator current, as can be seen in (11). Hence, $\delta T_{e}$ based prediction vectors have been considered in this study.

TABLE III

STATOR FLUX POSITION AND STATOR FLUX ERROR DEPENDENT ACTIVE PREDICTION VECTORS

\begin{tabular}{|l|l|l|l|l|l|l|}
\hline$\delta \psi_{s}$ & I & II & III & IV & V & VI \\
\hline$\delta \psi_{s}>0$ & $\mathbf{v}_{6}, \mathbf{v}_{2}$ & $\mathbf{v}_{1}, \mathbf{v}_{3}$ & $\mathbf{v}_{2}, \mathbf{v}_{4}$ & $\mathbf{v}_{3}, \mathbf{v}_{5}$ & $\mathbf{v}_{4}, \mathbf{v}_{6}$ & $\mathbf{v}_{1}, \mathbf{v}_{5}$ \\
\hline$\delta \psi_{s}<0$ & $\mathbf{v}_{3}, \mathbf{v}_{5}$ & $\mathbf{v}_{4}, \mathbf{v}_{6}$ & $\mathbf{v}_{1}, \mathbf{v}_{5}$ & $\mathbf{v}_{6}, \mathbf{v}_{2}$ & $\mathbf{v}_{1}, \mathbf{v}_{3}$ & $\mathbf{v}_{2}, \mathbf{v}_{4}$ \\
\hline
\end{tabular}

\section{B. Optimal voltage vector selection}

Since two adjacent voltage vectors are selected for prediction and actuation, only one switching transition takes place at a particular time instant under the conditions mentioned in the section IV-A. Hence, the average switching frequency is reduced, and no need to include the switching frequency term in the cost function. It also reduces the computational burden of the proposed control strategy. The cost function used in the proposed FS-PDTC is as follows:

$g=\left|T_{e}^{*}(k+1)-T_{e}^{p}(k+1)\right|+\lambda_{p}|| \vec{\psi}_{s}^{*}|-| \vec{\psi}_{s}^{p}(k+1)||+I_{m}$.

It is obvious that the selection of weighting factors (19) is simpler compared with (16) used in the conventional FS-PTC.

In a real time implementation, calculation time of a control algorithm introduces one step time delay which must be compensated [28]. It is done by two steps ahead prediction. The predicted stator flux $\vec{\psi}_{s}^{p}(k+1)(12)$ and stator current $\vec{i}_{s}^{p}(k+1)$ (13) are used as the initial states for the predictions at time instant $k+2$. In order to predict $\vec{\psi}_{s}^{p}(k+1)$ and $\vec{i}_{s}^{p}(k+1)$, the optimal voltage vector $\mathbf{v}_{\text {opt }}(k)$ applied to the motor terminal at instant $k$ is employed in (12) and (13), respectively. In this case, for the selection of prediction vectors, $\vec{\psi}_{s}^{p}(k+1)$ instead of $\overrightarrow{\hat{\psi}}_{s}(k)$ and $T_{e}^{p}(k+1)$ instead of $\hat{T}_{e}(k)$ will be used for the calculations of $\hat{\theta}_{s}(17)$ and $\delta T_{e}$, respectively.

Hence, for the implementation of delay compensation scheme [28], the optimal voltage vector is selected by minimizing the following cost function

$g=\left|T_{e}^{*}(k+2)-T_{e}^{p}(k+2)\right|+\lambda_{p}|| \vec{\psi}_{s}^{*}|-| \vec{\psi}_{s}^{p}(k+2)||+I_{m}$.

\section{Average switching frequency reduction}

The selection of only one zero vector, either $\mathbf{v}_{0}$ or $\mathbf{v}_{7}$, with two active vectors for prediction and actuation may increase the average switching frequency. For this reason, if $\mathbf{v}_{0}$ is selected as the optimal voltage vector, an appropriate zero vector, either $\mathbf{v}_{0}$ or $\mathbf{v}_{7}$, will be selected in such a way that only one switching transition takes place at a particular time instant. For example, if the applied voltage vector at the time instant $k$ is $\mathbf{v}_{2}(110)$ and the optimal voltage vector actuated for the next time instant $k+1$ is $\mathbf{v}_{0}$, then the switching state " 111 " will be selected instead of " 000 " as the optimal switching state. Hence, the state " 000 " will be selected after " $100 "$, " 010 ", and "001", otherwise " 111 " will be selected as zero vector.

\section{Overall control structure}

The complete schematic of the proposed FS-PDTC are shown in Fig. 4, which mainly includes four parts: rotor and stator flux estimation, prediction vectors selection, stator flux and torque prediction, and cost function optimization (optimal voltage vector selection). Rotor speed is measured using an encoder mounted on the motor shaft. The measured rotor speed and stator current are feedback to the predictive controller. The measured speed is also compared with the reference speed, and the error is processed through a proportional-integral (PI) controller to produce the reference torque. The constant rated stator flux reference is commanded from the outside of the controller, as field-weakening has not been considered in the present analysis. Both of the aforementioned reference quantities are directly used in the cost function to actuate the optimal voltage vector.

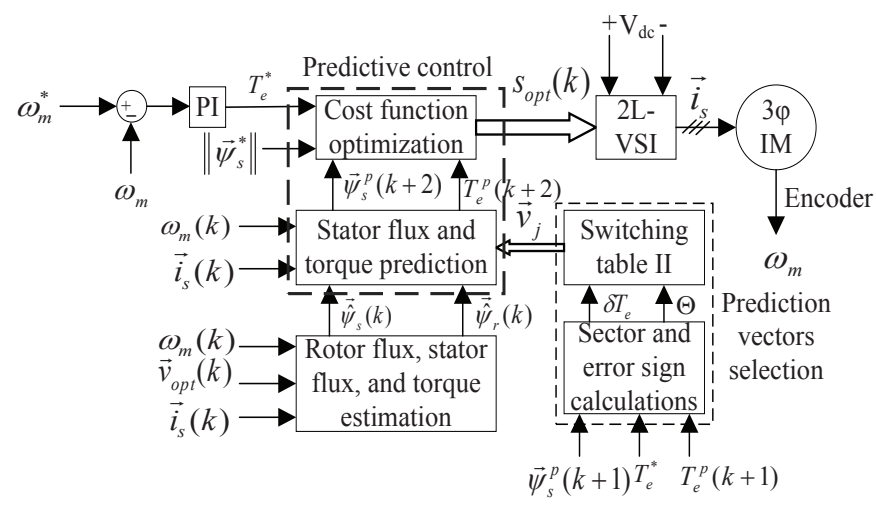

Fig. 4. Proposed control system.

\section{PROPOSED CONTROL ALGORITHM}

The overall control procedure can be summarized by the following sequences:

Step 1) Measure: Sampling $\mathbf{i}_{\mathbf{s}}(k), V_{d c}(k)$, and $\omega_{m}(k)$.

Step 2) Apply: Apply the optimal voltage vector $\mathbf{v}_{\mathbf{o p t}}(k)$.

Step 3) Estimate: Estimate the rotor flux $\overrightarrow{\hat{\psi}}_{r}(k)$ and the stator flux $\overrightarrow{\hat{\psi}}_{s}(k)$ using (9) and (10), respectively.

Step 4) Predict: Predict the stator flux $\vec{\psi}_{s}^{p}(k+1)$, the stator current $\vec{i}_{s}^{p}(k+1)$, and the torque $T_{e}^{p}(k+1)$ using (12)-(14).

Step 5) Select prediction vectors: Select the active prediction vectors using Table II.

Step 6) Predict and actuate: Predict the stator flux $\vec{\psi}_{s}^{p}(k+$ $2)$, the stator current $\vec{i}_{s}^{p}(k+2)$, and the torque $T_{e}^{p}(k+2)$ taking one step forward of (12)-(14) to overcome one step delay caused by digital implementation. Then evaluate the predicted stator flux and torque by actuating a predefined cost function (20).

Step 7) Optimize: Select $\mathbf{v}_{\mathbf{o p t}}(k+2)$ which results minimum $g(20)$ and also replace it with an appropriate zero vector if selected $\mathbf{v}_{\text {opt }}(k+2)$ is a zero vector. Return to step 1. 


\section{COMPUTATIONAL EFFICIENCY OF THE PROPOSED FS-PDTC ALGORITHM}

The execution time of the proposed control algorithm is reduced, since the number of prediction vectors is less. The proposed algorithm requires an additional calculation that was not in the traditional PTC, for the stator flux position and the prediction vectors selection. However, the calculations are very simple, and therefore, the required extra execution time is much less than the time reduced in the prediction and actuation steps. The execution time of the proposed algorithm compared

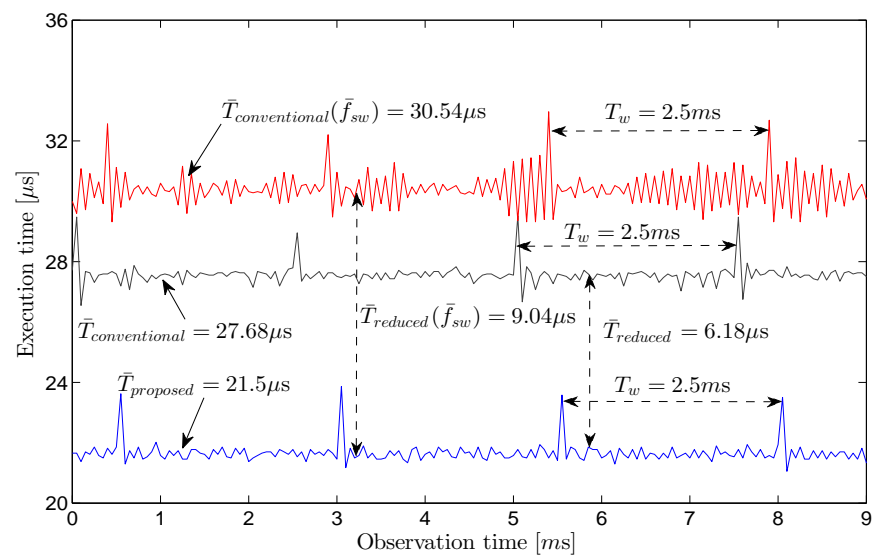

Fig. 5. Execution time of the proposed and the conventional control algorithms.

with the conventional control algorithm is shown in Fig. 5.

It is seen that the average execution time of the conventional FS-PTC algorithm $\bar{T}_{\text {conventional }}$ without switching transition term in the cost function is $27.68 \mu \mathrm{s}$, which is further increased to $30.54 \mu \mathrm{s}$ if the switching transition term is included in the cost function. On the other hand, the average execution time of the proposed algorithm $\bar{T}_{\text {proposed }}$ is $21.5 \mu \mathrm{s}$. Hence, the reduced average execution times with and without switching transition term in the cost function are $29.6 \%$ and $22.33 \%$, respectively. Since the speed control loop is executed in every $2.5 \mathrm{~ms}$, it is seen that the execution time is increased in every $2.5 \mathrm{~ms}$. A comparison of average execution times is shown in Table IV.

TABLE IV

COMPARISON OF AVERAGE EXECUTION TIMES BETWEEN THE PROPOSED AND THE CONVENTIONAL CONTROL ALGORITHMS.

\begin{tabular}{lccc}
\hline \hline Execution time & $\begin{array}{c}\text { Conventional } \\
(\mu \mathrm{s})\end{array}$ & $\begin{array}{c}\text { Conventional } \\
\left(\bar{f}_{s w}\right)(\mu \mathrm{s})\end{array}$ & $\begin{array}{c}\text { Proposed } \\
(\mu \mathrm{s})\end{array}$ \\
\hline \hline Measurement & 6.63 & 6.67 & 6.64 \\
Prediction and actuation & 27.68 & 30.54 & 20.26 \\
Flux position & 0 & 0 & 1.24 \\
Total & 38.3 & 42.2 & 30.76 \\
\hline \hline
\end{tabular}

\section{EXPERIMENTAL SETUP}

In order to verify the performance of the proposed FS-PTC strategy, some experiments are carried out in the laboratory. The setup is composed by a squirrel-cage IM driven by an IGBT based 2L-VSI of $1200 \mathrm{~V}$ with maximum current rating of $50 \mathrm{~A}$. The parameters of the IM have been obtained by conventional tests, and listed in Table V. A permanent magnet dc machine is used as load and coupled to the motor shaft. An incremental encoder of $5000 \mathrm{p} / \mathrm{rev}$ is also equipped with motor shaft to measure the speed. The control algorithm is implemented using dSPACE DS1104 R\&D controller board with ControlDesk and MATLAB Simulink software packages. The controller parameters and the load specifications are presented in Table VI. The outer speed loop of the controller is sampled in every $2.5 \mathrm{~ms}$ to minimize the quantization error. For the estimation, prediction and actuation of the objective function, a sampling time is set to $50 \mu \mathrm{s}$.

TABLE V

A $415 \mathrm{~V}, 3-\phi, 50 \mathrm{~Hz}$ INDUCTION MOTOR PARAMETERS

\begin{tabular}{|l|l|}
\hline$R_{s}=6.03 \Omega$ & $\psi_{\text {snom }}=1.0 \mathrm{~Wb}$ \\
\hline$R_{r}=6.085 \Omega$ & $T_{\text {nom }}=7.4 \mathrm{Nm}$ \\
\hline$L_{s}=0.5192 \mathrm{H}$ & $N_{p}=2$ \\
\hline$L_{r}=0.5192 \mathrm{H}$ & $J=0.011787{\mathrm{Kg} . \mathrm{m}^{2}}^{2}$ \\
\hline$L_{m}=0.4893 \mathrm{H}$ & $\omega_{m}=1415 \mathrm{rpm}$ \\
\hline
\end{tabular}

TABLE VI

CONTROLLER PARAMETERS AND LOAD SPECIFICATIONS

\begin{tabular}{|l||l|}
\hline Controller parameters & Load specifications \\
\hline$k_{p}=0.396, k_{i}=9.056$ & $P=1.1 \mathrm{~kW}, \mathrm{~V}=180 \mathrm{~V}$ \\
$\lambda_{p}=30, \lambda_{n}=0.05$ & $I_{a}=6.9 \mathrm{~A}$ \\
$I_{\max }=4.5 \mathrm{~A}$ & $\omega=1800 \mathrm{rpm}$ \\
\hline
\end{tabular}

\section{EXPERIMENTAL RESULTS}

The performances of the proposed FS-PDTC are compared with two cases of the conventional FS-PTC: without and with including switching transition term in the cost function. All the voltage vectors $\left\{\mathbf{v}_{0} \cdots \mathbf{v}_{7}\right\}$ are evaluated if switching transition term is considered in the cost function. Otherwise, seven different voltage vectors are evaluated and then appropriate zero voltage vector (either $\mathbf{v}_{0}$ or $\mathbf{v}_{7}$ ) is selected, as explained in section IV-C.

The following investigations were carried out to test the effectiveness of the proposed FS-PDTC algorithm:

a) transient capability of the FS-PDTC under rated-speed reversal,

b) steady-state behavior at medium- and low-speed operation,

c) investigation of average switching frequency,

d) robustness against external rated-load disturbance,

e) step rated-torque transient characteristics, and

f) step rated-speed transient characteristics.

\section{A. Investigation of transient capability under rated-speed re- versal}

Firstly, a reverse speed operation of the proposed FSPDTC system at rated speed of $1415 \mathrm{r} / \mathrm{min}$ without load is performed, and the behavior of the control system is presented in Fig. 6(a). From top to bottom, the curves are the speed, stator current, estimated torque, and stator flux. The stator flux is constant at its nominal value of $1.0 \mathrm{~Wb}$. For comparison, 

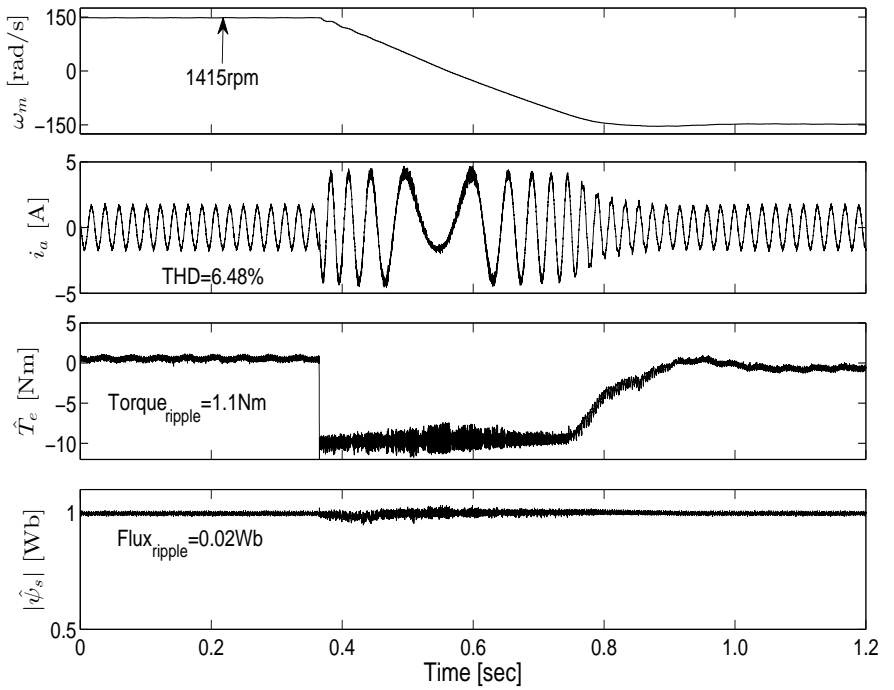

(a) Proposed
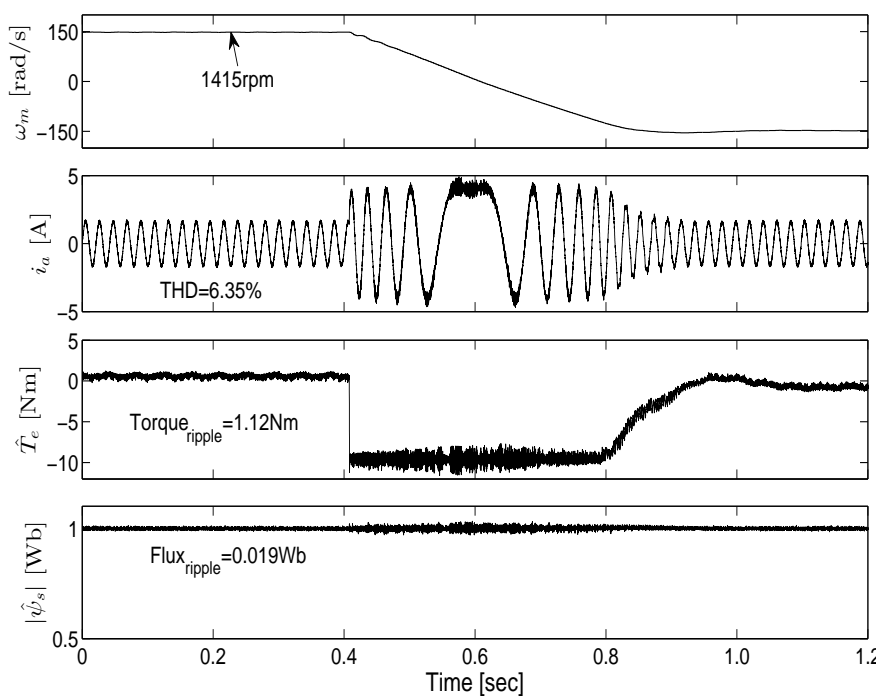

(b) Conventional

Fig. 6. Experimental waveforms of speed, stator current, estimated torque, and estimated stator flux under rated speed $(1415 \mathrm{r} / \mathrm{min})$ reversal condition.

same curves are plotted for the conventional FS-PTC where switching transition term is not included in the cost function, as shown in Fig. 6(b). It is clearly seen that the performances in terms of torque and flux ripples are comparable. During speed reversal, the ripples are slightly increased for both proposed and conventional control systems. It is because high current flowing through the stator winding. The total harmonic distortion (THD) of the stator current $i_{a}$, calculated with 10 cycles up to $10 \mathrm{kHz}$ using MATLAB powergui, for the proposed FS-PDTC is $6.48 \%$, whereas it is $6.35 \%$ for the conventional FS-PTC. It is noted that the average switching frequencies, calculated by the number of switching transitions per semiconductor device per second, are $1.91 \mathrm{kHz}$ and 2.11 $\mathrm{kHz}$ for the proposed and the conventional control systems, respectively.

From Fig. 6(a), it can be noted that a very small dip is present in the stator flux response during speed reversal. It is because the prediction vectors are selected based on the torque deviation (switching Table II) regardless of the stator flux deviation. During transient, the vector that produces more torque is selected and is applied to the motor terminal. Moreover, the vector producing more torque, in most cases, decreases stator flux and causes flux transient. One possible solution of this problem is to set higher value of the weighting factor $\lambda_{p}$ in (19) during transient than steady-state condition. Another possible solution is to use stator flux deviation based prediction vectors (switching Table III). In that case, less priority should be set on stator flux - small $\lambda_{p}$, compared with the torque deviation based prediction vectors in order to achieve satisfactory torque and flux performances.

\section{B. Steady-state behavior at medium- and low-speed opera- tions}

The steady state characteristics of the proposed and the conventional control systems at a speed of $1000 \mathrm{r} / \mathrm{min}$ with 4.0 Nm have been shown in Figs. 7(a) and 7(b), respectively. It is observed that the torque and flux ripples are very similar. However, the THD of stator current for the proposed FS-PDTC is bit higher due to lower average switching frequency. The frequency spectra of stator current using the proposed and the conventional control algorithms are presented in Figs. 8(a) and 8(b), respectively. It is observed that the average switching frequency $\bar{f}_{s w}$ for the proposed control algorithm is lower by $16.62 \%$, and the frequency spectrum is less distributed in a wide frequency range compared with the conventional control algorithm. In order to reduce the average switching frequency of the conventional FS-PTC, a switching transition term is added in the cost function. Then a weighting factor is imposed on the frequency term, provided that the torque and flux ripples are almost similar. The responses of the system and the frequency spectrum of the stator current are presented in Figs. 7(c) and 8(c), respectively. It is seen that the THD of stator current is almost similar to the proposed control, but the average switching frequency is still higher. If greater weight is imposed on the switching transition term to reduce the average switching frequency further, while keeping the weight of stator flux error constant, the torque ripple increases. Hence, proper selection of weighting factors is a complex task. In this sense, the proposed FS-PDTC is simpler compared with the conventional FS-PTC. A comparison of the steady state performances is presented in Table VII.

TABLE VII

COMPARISON BETWEEN THE CONVENTIONAL AND THE PROPOSED CONTROL SCHEMES WITH $\omega_{m}=1000 \mathrm{r} / \mathrm{min}, T_{l}=4 \mathrm{Nm}$, AND $T_{s}=50 \mu s$.

\begin{tabular}{lccc}
\hline \hline Index & Conventional $\left(f_{s w}\right)$ & Conventional & Proposed \\
\hline \hline THD (for $\left.i_{a}\right)$ & $5.77 \%$ & $5.55 \%$ & $5.75 \%$ \\
Torque ripple & $1.40 \mathrm{Nm}$ & $1.26 \mathrm{Nm}$ & $1.30 \mathrm{Nm}$ \\
Flux ripple & $0.03 \mathrm{~Wb}$ & $0.028 \mathrm{~Wb}$ & $0.026 \mathrm{~Wb}$ \\
Average Switching & $2.97 \mathrm{kHz}$ & $3.43 \mathrm{kHz}$ & $2.86 \mathrm{kHz}$ \\
frequency $\left(\bar{f}_{s w}\right)$ & & & \\
\hline \hline
\end{tabular}

In order to test the low speed performance, the machine is operated at $300 \mathrm{r} / \mathrm{min}$ with $50 \%$ of the rated load. The waveforms corresponding to the proposed and the conventional 

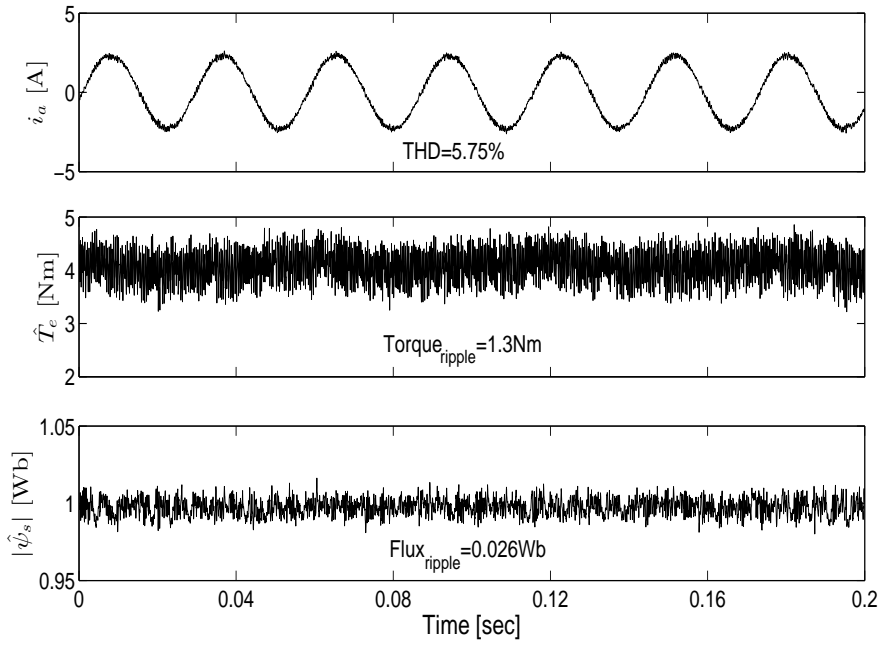

(a) Proposed
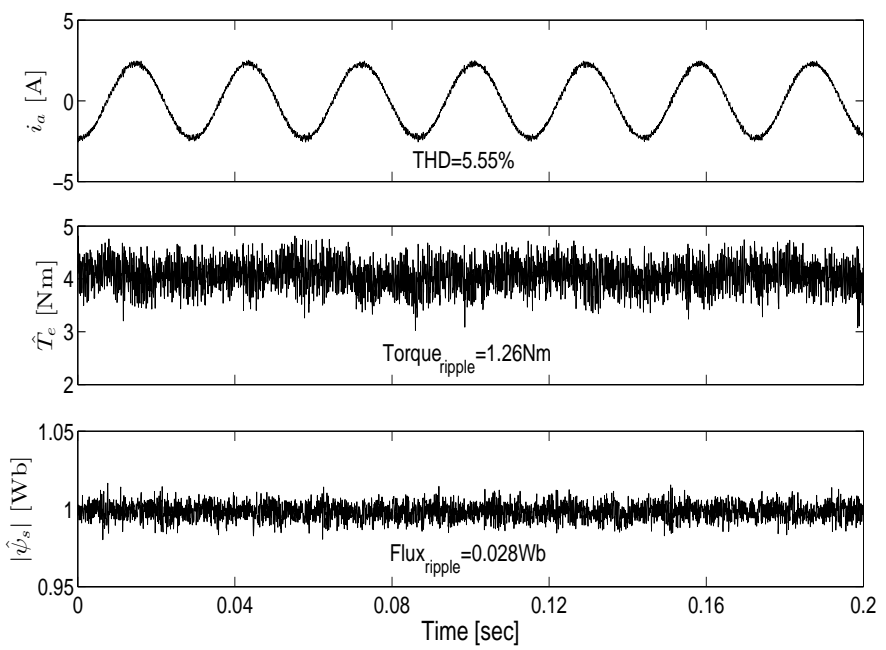

(b) Conventional
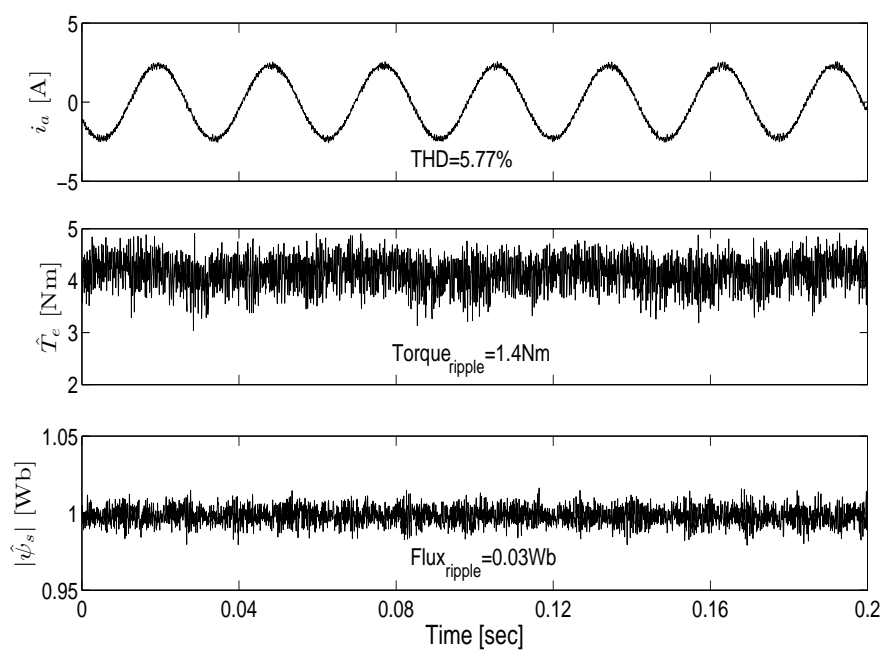

(c) Conventional with average switching frequency reduction

Fig. 7. Experimental steady state waveforms of stator current, estimated torque, and estimated stator flux at $1000 \mathrm{r} / \mathrm{min}$ with $4.0 \mathrm{Nm}$ load.

control algorithms are presented in Figs. 9(a) and 9(b), respectively. It is observed that THD of stator current, torque ripple, and flux ripple are very similar, provided that the switching

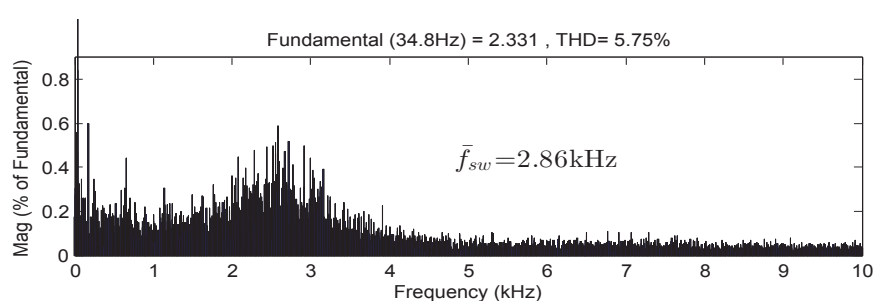

(a)

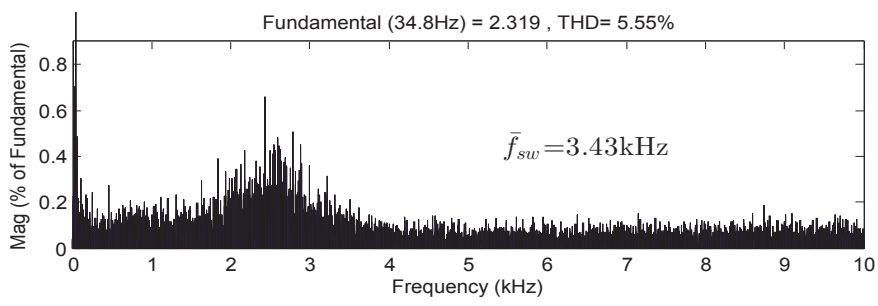

(b)

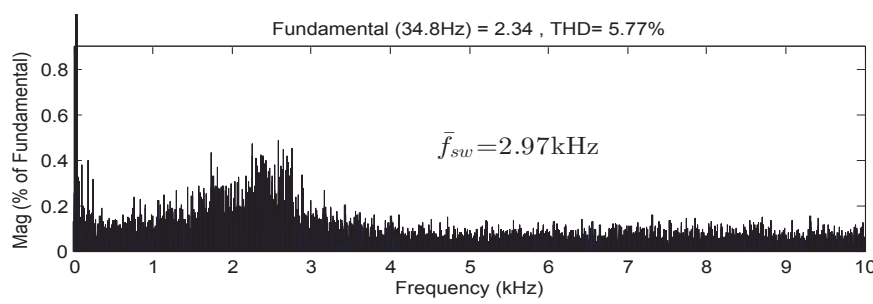

(c)

Fig. 8. Experimental frequency spectra of stator current $i_{a}$ at $1000 \mathrm{r} / \mathrm{min}$ using (a) Proposed algorithm, (b) conventional algorithm, and (c) conventional algorithm with average switching frequency reduction.

frequency term is not included in the cost function. From the frequency spectra of stator current, as shown in Figs. 10(a) and $10(\mathrm{~b})$, it is seen that the average switching frequency of the proposed FS-PDTC is $4.90 \mathrm{kHz}$; on the other hand, it is $4.83 \mathrm{kHz}$ for the conventional FS-PTC. If average switching frequency reduction is considered, the THD of stator current is increased from $5.21 \%$ to $5.60 \%$, as shown in Fig. 9(c), yielding slightly higher torque ripple by $0.05 \mathrm{Nm}$. However, the average switching frequency is reduced, as shown in Fig. 10(c), from $4.83 \mathrm{kHz}$ to $4.72 \mathrm{kHz}$. Note that the improvement of average switching frequency, while keeping torque and flux ripples similar, is not significant at low speed. It is particularly important to note that the frequency spectrum for the proposed FS-PDTC algorithm is less distributed in a wide frequency range compared with the both cases of conventional FS-PTC algorithms.

\section{Investigation of average switching frequency}

The average switching frequencies for the proposed and the conventional control algorithms for different speeds and different loading conditions are presented in Fig. 11(a). It is seen that the average switching frequencies are comparable at very low and high speeds with $50 \%$ or higher of nominal load. The reduction of average switching frequencies for the proposed FS-PDTC is significant-maximum $24.56 \%$ of average switching frequency, for the speed range of 400-1200 $\mathrm{r} / \mathrm{min}$, as can be seen in Fig. 11(b). 

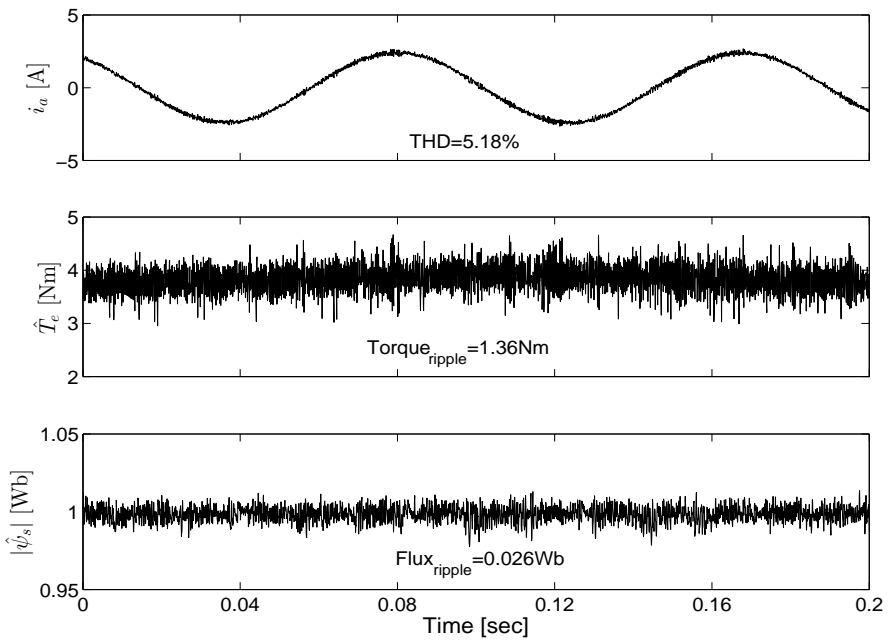

(a) Proposed
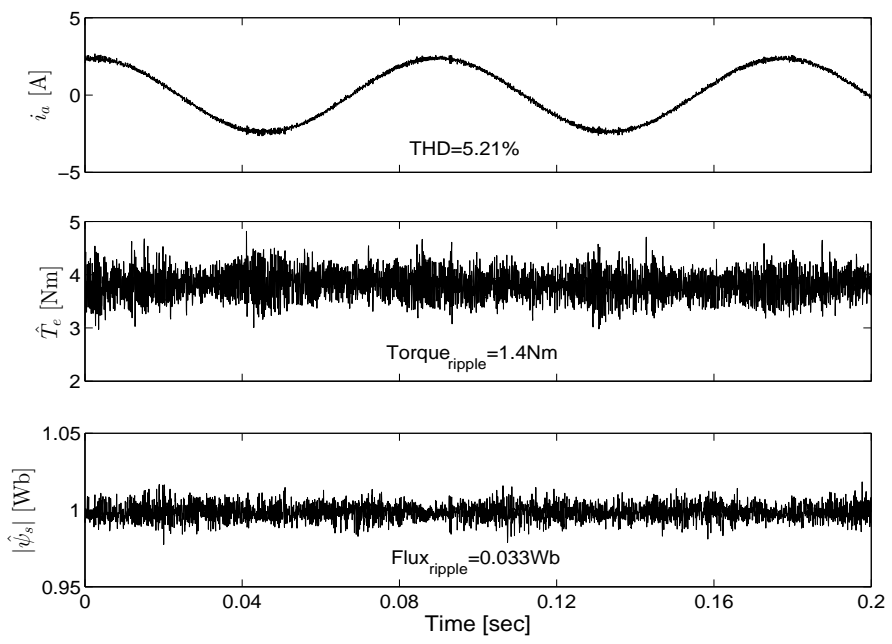

(b) Conventional
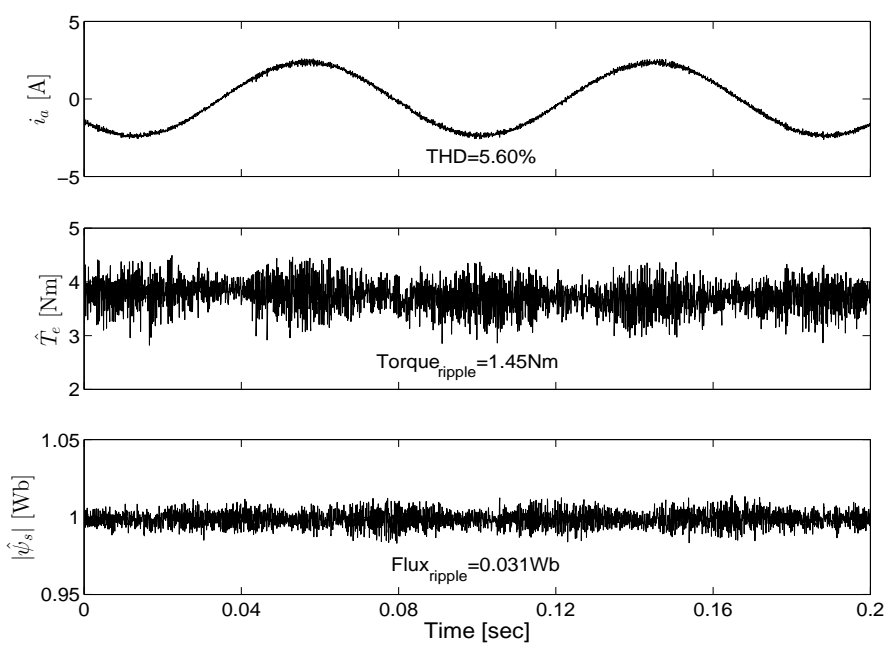

(c) Conventional with average switching frequency reduction

Fig. 9. Experimental steady state waveforms of stator current, estimated torque, and estimated stator flux at $300 \mathrm{r} / \mathrm{min}$ with $50 \%$ of nominal load.

\section{Investigation of robustness against rated-load disturbance}

The responses to external load disturbance are illustrated in Figs. 12(a) and 12(b) for the proposed and the conventional

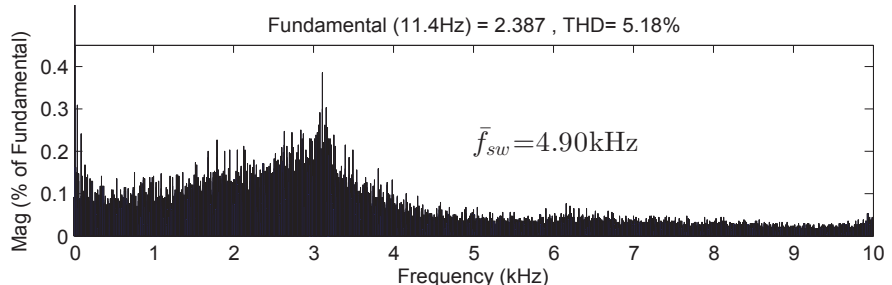

(a)

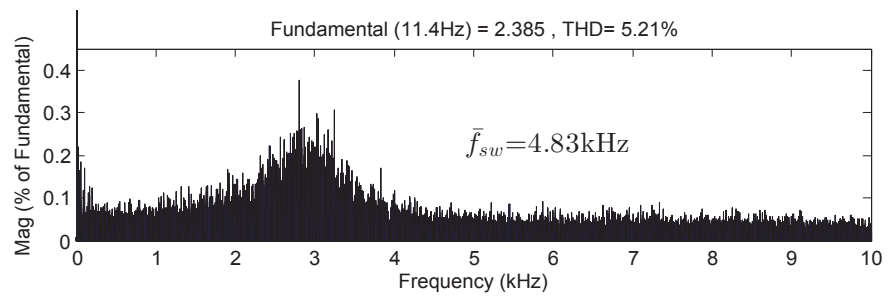

(b)

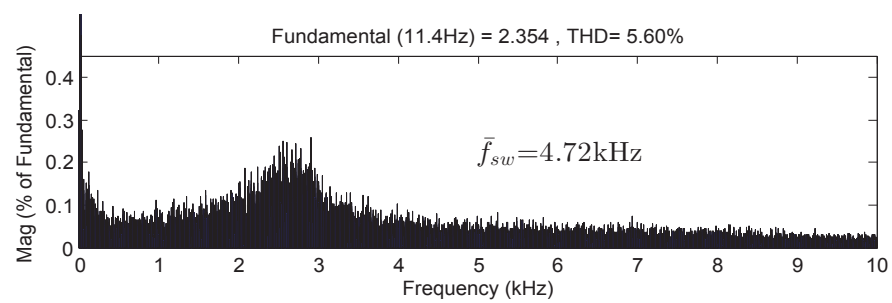

(c)

Fig. 10. Experimental frequency spectra of the stator current $i_{a}$ at $300 \mathrm{r} / \mathrm{min}$ using (a) proposed algorithm, (b) conventional algorithm, and (b) conventional algorithm with average switching frequency reduction.

control algorithms, respectively. The load, which is dependent on rotor speed, is suddenly changed from 0 (no-load) to 7.4 $\mathrm{Nm}$ (full-load) at $1000 \mathrm{r} / \mathrm{min}$. For both cases, it is observed that the stator current THD and the torque and flux ripple are very similar before and after added load. It is also seen that the motor speed returns to its original value within a very short time, and the speed responses are also identical during load disturbance. The average switching frequencies for the proposed FS-PDTC algorithm before and after added load are $3.02 \mathrm{kHz}$ and $2.60 \mathrm{kHz}$, respectively. Whereas, the average switching frequencies before and after added load are 3.67 $\mathrm{kHz}$ and $3.09 \mathrm{kHz}$, respectively, for the conventional FS-PTC algorithm. For both cases, during load change, the stator flux remains constant at its rated value, which completely ensures decoupled control of torque and flux.

\section{E. Step rated-torque transient characteristics}

Step rated-torque transient characteristics of the proposed FS-PDTC have been tested, and illustrated in Fig. 13. A step rated-torque reference of $7.4 \mathrm{Nm}$ is commanded. It is seen that the torque rise times of the proposed and the conventional control algorithms are very close with $0.5 \mathrm{~ms}$ versus 0.53 $m \mathrm{~s}$, respectively. Both control algorithms exhibit fast dynamic response that indicate the equivalency of the proposed and the conventional control algorithms under rated-torque transient condition. 


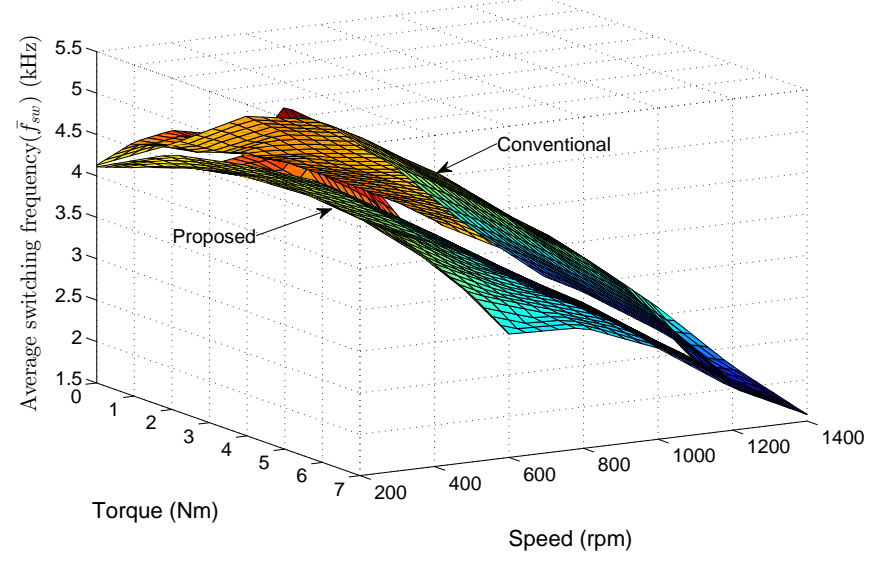

(a) Average switching frequencies

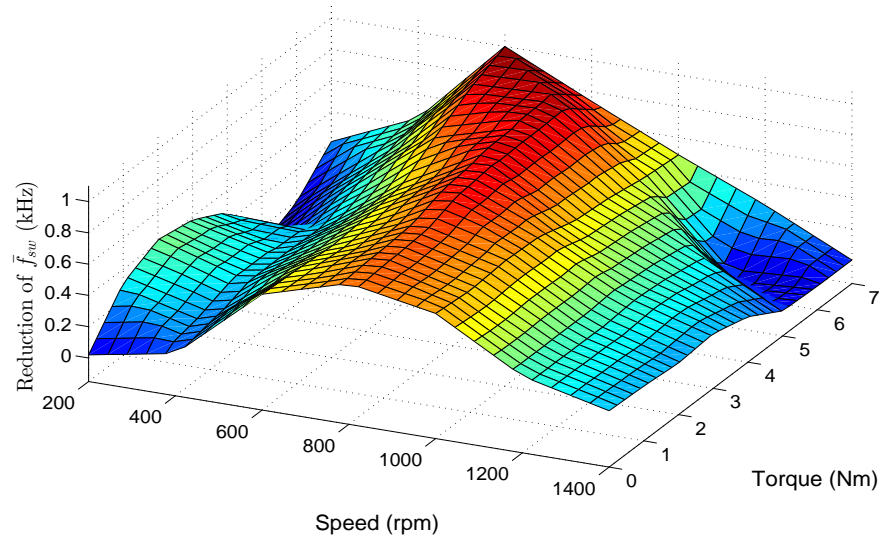

(b) Reduction of average switching frequencies

Fig. 11. Experimental average switching frequencies and the reduction of average switching frequencies from $200-1400 \mathrm{r} / \mathrm{min}$ and $0-7 \mathrm{Nm}$.

\section{F. Step rated-speed transient characteristics}

Finally, rated-speed transient behavior of the proposed control algorithm is investigated and is presented in Fig. 14. Initially, the machine is started with $100 \mathrm{r} / \mathrm{min}$, and then suddenly a step rated-speed reference of $1415 \mathrm{r} / \mathrm{min}$ is commanded. Similar to the conventional control algorithm, the proposed FS-PDTC can track the reference speed accurately without any significant overshoot, as can be seen in Fig. 14. Also note that the speed rise times of the both control algorithms are comparable.

\section{CONCLUSion}

This paper has presented a simplified FS-PDTC algorithm that employs only three voltage vectors instead of eight used in the conventional FS-PTC for prediction and actuation. The number of prediction vectors is reduced without any complex calculations. A reduction of the average switching frequency of each semiconductor switch is achieved by not taking into account the switching transition term in the cost function, as is the case in the conventional FS-PTC. The variation range of average switching frequency is also reduced. The reduced number of control objectives in the cost function makes the selection of weighting factors simpler than the conventional
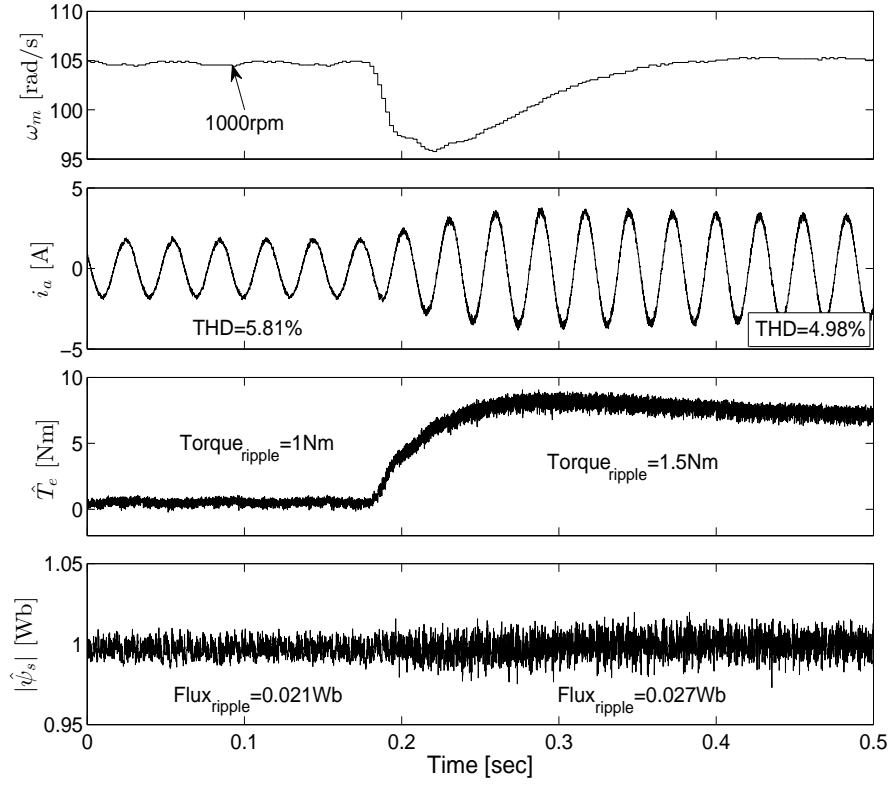

(a) Proposed
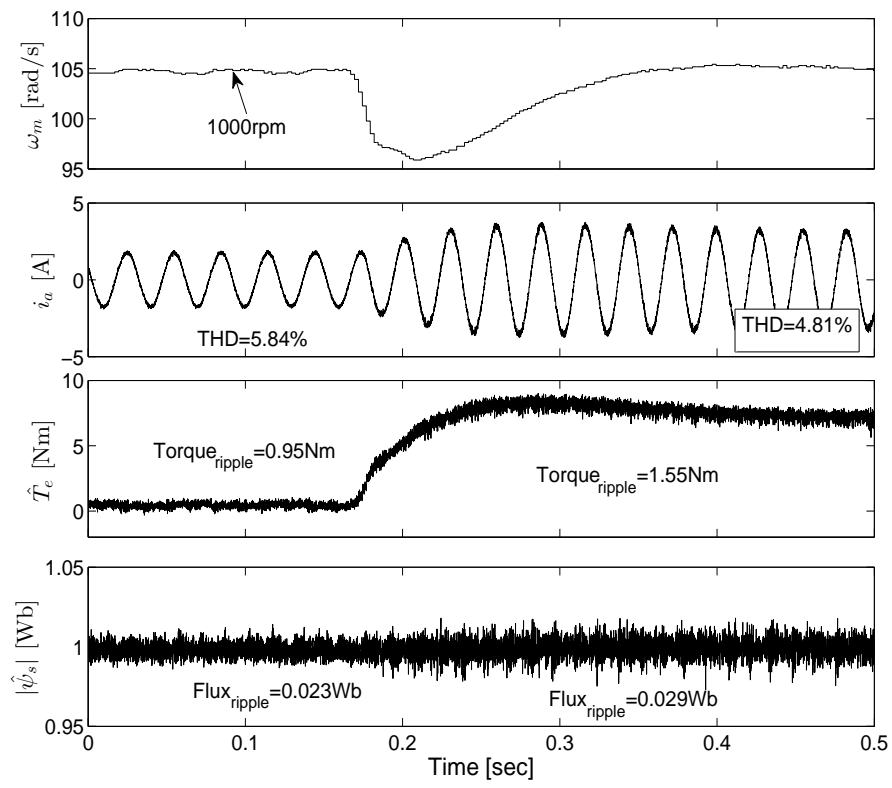

(b) Conventional

Fig. 12. Experimental responses to external rated load disturbance at 1000 $\mathrm{r} / \mathrm{min}$.

method. The proposed FS-PDTC algorithm is verified by experiment. The maximum reduction of the average execution time and the average switching frequency of each semiconductor switch are $29.6 \%$ and $24.56 \%$ of the conventional FSPTC, respectively. This was achieved without sacrificing the torque and flux performances achieved in the conventional method. Good performances in terms of stator current THD, robustness against load disturbance, step torque response, and step speed response are also achieved by using the proposed FS-PDTC. The reduction of the computational burden may help incorporation of machine parameter estimation and more elaborate inverters such as multilevel and matrix converters within the FS-PTC IM drive strategy investigated in this paper. 

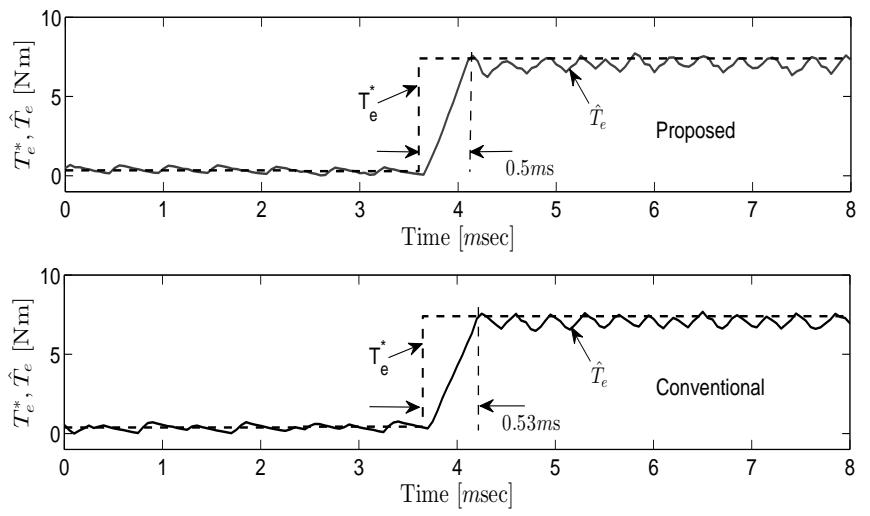

Fig. 13. Experimental step rated-torque responses of the proposed and the conventional control algorithms.
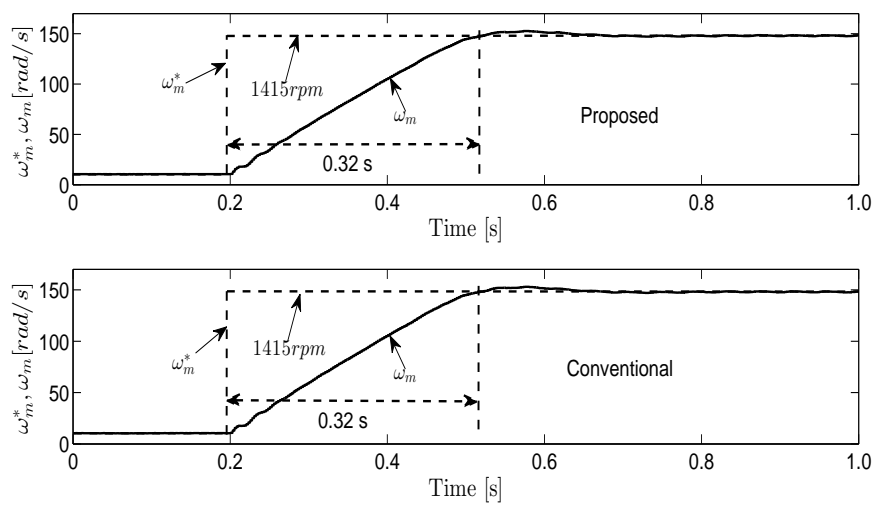

Fig. 14. Experimental step rated-speed transient of the proposed and the conventional control algorithms.

\section{REFERENCES}

[1] S. Kouro, P. Cortes, R. Vargas, U. Ammann, and J. Rodriguez, "Model predictive control-a simple and powerful method to control power converters," IEEE Trans. on Ind. Electron., vol. 56, no. 6, pp. 18261838, Jun. 2009.

[2] J. Rodriguez, M. P. Kazmierkowski, J. R. Espinoza, P. Zanchetta, H. Abu-Rub, H. A. Young, and C. A. Rojas, "State of the art of finite control set model predictive control in power electronics," IEEE Trans. on Ind. Informatics, vol. 9, no. 2, pp. 1003-1016, May 2013.

[3] P. Cortes, M. P. Kazmierkowski, R. M. Kennel, D. Quevedo, and J. Rodriguez, "Predictive control in power electronics and drives," IEEE Trans. on Ind. Electron., vol. 55, no. 12, pp. 4312-4324, Dec. 2008.

[4] M. H. Vafaie, B. Mirzaeian Dehkordi, P. Moallem, and A. Kiyoumarsi, "A new predictive direct torque control method for improving both steady-state and transient-state operations of the pmsm," IEEE Trans. on Power Electron., vol. 31, no. 5, pp. 3738-3753, May 2016.

[5] Y. Zhang and H. Yang, "Generalized two-vector-based model-predictive torque control of induction motor drives," IEEE Trans. on Power Electron., vol. 30, no. 7, pp. 3818-3829, July 2015.

[6] T. Geyer, "Model predictive direct torque control: Derivation and analysis of the state-feedback control law," IEEE Trans. on Ind. Appl., vol. 49, no. 5, pp. 2146-2157, Sept. 2013.

[7] Y. Zhang and H. Yang, "Model predictive torque control of induction motor drives with optimal duty cycle control," IEEE Trans. on Power Electron., vol. 29, no. 12, pp. 6593-6603, Dec. 2014.

[8] I. Takahashi and T. Noguchi, "A new quick-response and high-efficiency control strategy of an induction motor," IEEE Trans. on Ind. Appl., vol. IA-22, no. 5, pp. 820-827, Sept. 1986.

[9] T. Geyer, "Computationally efficient model predictive direct torque control," IEEE Trans. on Power Electron., vol. 26, no. 10, pp. 2804 2816, Oct. 2011.
[10] F. Wang, Z. Zhang, R. Kennel, and J. Rodriguez, "Model predictive torque control with an extended prediction horizon for electrical drive systems," Int. Journal of Control, pp. 1-10, Aug. 2014.

[11] C. Xia, T. Liu, T. Shi, and Z. Song, "A simplified finite-control-set model-predictive control for power converters," IEEE Trans. on Ind. Informatics, vol. 10, no. 2, pp. 991-1002, May 2014.

[12] Y. Zhang and H. Lin, "Simplified model predictive current control method of voltage-source inverter," in Proc. of ICPE ECCE, May 2011, pp. $1726-1733$.

[13] P. Cortes, A. Wilson, S. Kouro, J. Rodriguez, and H. Abu-Rub, "Model predictive control of multilevel cascaded h-bridge inverters," IEEE Trans. on Ind. Electron., vol. 57, no. 8, pp. 2691-2699, Aug. 2010.

[14] A. Iqbal, H. Abu-Rub, S. K. M. Ahmed, P. Cortes, and J. Rodriguez, "Model predictive current control of a three-level five-phase NPC VSI using simplified computational approach," in Proc. of APEC, Mar. 2014, pp. 2323-2330.

[15] Y. Zhang, W. Xie, Z. Li, and Y. Zhang, "Low-complexity model predictive power control: Double-vector-based approach," IEEE Trans. on Ind. Electron., vol. 61, no. 11, pp. 5871-5880, Nov. 2014.

[16] J. Hu, J. Zhu, G. Lei, G. Platt, and D. G. Dorrell, "Multi-objective modelpredictive control for high-power converters," IEEE Trans. on Energy Conv., vol. 28, no. 3, pp. 652-663, Sept. 2013.

[17] M. Habibullah and D. Lu, "A speed-sensorless FS-PTC of induction motors using extended Kalman filters," IEEE Trans. on Ind. Electron., vol. 62, no. 11, pp. 6765-6778, Nov. 2015.

[18] W. Xie, X. Wang, F. Wang, W. Xu, R. M. Kennel, D. Gerling, and R. D. Lorenz, "Finite-control-set model predictive torque control with a deadbeat solution for PMSM drives," IEEE Trans. on Ind. Electron., vol. 62, no. 9, pp. 5402-5410, Sep. 2015.

[19] M. Habibullah, D. Lu, D. Xiao, and M. F. Rahman, "A computationally efficient FS-PTC for im with minimum voltage vectors," in Proc. of IEEE Int. Conf. on Power Electron. and Drive Systems (PEDS), June 2015, pp. 992-997.

[20] S. Alireza Davari, D. A. Khaburi, and R. Kennel, "An improved FCSMPC algorithm for an induction motor with an imposed optimized weighting factor," IEEE Trans. on Power Electron., vol. 27, no. 3, pp. 1540-1551, Mar. 2012

[21] T. J. Vyncke, S. Thielemans, T. Dierickx, R. Dewitte, M. Jacxsens, and J. A. Melkebeek, "Design choices for the prediction and optimization stage of finite-set model based predictive control," in Workshop on Predictive Control of Electrical Drives and Power Electronics (PRECEDE), Oct. 2011, pp. 47-54.

[22] P. Cortes, S. Kouro, B. La Rocca, R. Vargas, J. Rodriguez, J. I. Leon, S. Vazquez, and L. G. Franquelo, "Guidelines for weighting factors design in model predictive control of power converters and drives," in Proc. of ICIT 2009, Feb. 2009, pp. 1-7.

[23] R. Vargas, U. Ammann, B. Hudoffsky, J. Rodriguez, and P. Wheeler, "Predictive torque control of an induction machine fed by a matrix converter with reactive input power control," IEEE Trans. on Power Electron., vol. 25, no. 6, pp. 1426-1438, Jun. 2010.

[24] P. Zanchetta, "Heuristic multi-objective optimization for cost function weights selection in finite states model predictive control," in Workshop on Predictive Control of Electrical Drives and Power Electronics (PRECEDE), Oct. 2011, pp. 70-75.

[25] C. A. Rojas, J. Rodriguez, F. Villarroel, J. R. Espinoza, C. A. Silva, and M. Trincado, "Predictive torque and flux control without weighting factors," IEEE Trans. on Ind. Electron., vol. 60, no. 2, pp. 681-690, Feb. 2013.

[26] T. Geyer, G. Papafotiou, and M. Morari, "Model predictive direct torque control-part I: Concept, algorithm, and analysis," IEEE Trans. on Ind. Electron., vol. 56, no. 6, pp. 1894-1905, Jun. 2009.

[27] J. Rodriguez and P. Cortes, Predictive Control of Power Converters and Electrical Drives. Wiley, 2012.

[28] P. Cortes, J. Rodriguez, C. Silva, and A. Flores, "Delay compensation in model predictive current control of a three-phase inverter," IEEE Trans. on Ind. Electron., vol. 59, no. 2, pp. 1323-1325, Feb. 2012. 


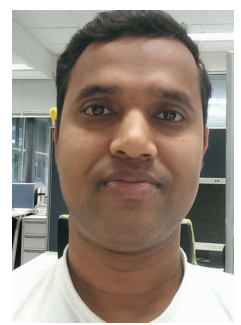

trical drives.

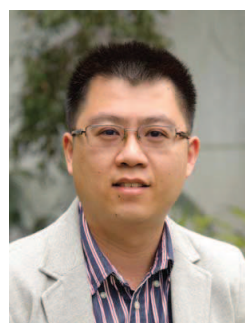

Dylan Dah-Chuan Lu (S'00 M'04 SM'09) received his B.Eng. (Hons.) and Ph.D. degrees in Electronic and Information Engineering from The Hong Kong Polytechnic University, Hong Kong in 1999 and 2004 respectively.

In 2003, he joined Power $^{e}$ Lab Ltd. as a Senior Design Engineer. His major responsibilities included project development and management, circuit design, and contribution of research in power electronics. In 2006, he joined the School of Electrical and Information Engineering, The University of Sydney, Australia, where he is currently an Associate Professor. He was a Visiting Associate Professor at the University of Hong Kong in 2013. He is the author and co-author of over 130 papers in the areas of power electronics and engineering education. He has two patents on efficient power conversion. His current research interests include power electronics circuits and control for efficient power conversion, lighting, renewable electrical energy systems, microgrids, motor drive and power quality improvement, and engineering education.

Dr. Lu is a member of the Institute of Engineers Australia. He presently serves as an Associate Editor for the IEEE Transactions on Circuits and Systems II. He also serves as an Associate Editor for the IET Renewable Power Generation and the International Journal of Electronics. He also served as a Guest Editor for the IEEE Transactions on Industrial Electronics; special issue on Power Converters, Control and Energy Management for Distributed Generation in July 2015 issue.

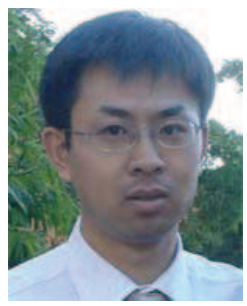

Dan Xiao received the bachelor's and master's degrees in electrical engineering from Shenyang University of Technology, Shenyang, China, in 2001 and 2004, respectively, and the Ph.D. degree in electrical engineering from the University of New South Wales (UNSW Australia), Sydney, Australia.

$\mathrm{He}$ is currently working in technical support for power engineering with UNSW Australia. His research interests are in sensorless control, matrix converters, and real-time digital simulation of microgrid and electrical drive systems.

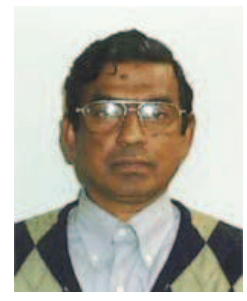

Muhammed Fazlur Rahman (F'14) received the B.Sc. Eng. Hons degree in electrical engineering from Bangladesh University of Engineering and Technology, Dhaka, Bangladesh, in 1972 and the M.Sc. and Ph.D. degrees from the University of Manchester, Manchester, U.K., in 1975 and 1978, respectively.

He subsequently worked as a Systems Design Engineer with the General Electric Projects Co. of U.K. at Rugby for two years before joining the National University of Singapore, Singapore, in 1980 He joined the University of New South Wales (UNSW Australia), Sydney, Australia, in 1988, as a Senior Lecturer. He is currently a Professor and Head of the Energy Systems Group with the School of Electrical Engineering and Telecommunications, UNSW Australia. His research interests are power electronics, motor drives, design of electrical machines with permanentmagnet excitation, and motion control systems. 